\title{
Role of Laser Iridoplasty in the Management of Angle Closure Mechanisms other than Pupillary Block
}

\author{
${ }^{1}$ Vitor Gomes Prado, ${ }^{2}$ Syril Dorairaj, ${ }^{3}$ Luis Gustavo Biteli, ${ }^{4}$ Aline KS Sousa, ${ }^{5}$ Pilar AM Moreno, \\ ${ }^{6}$ Flavio Siqueira Lopes, ${ }^{7}$ Tiago Santos Prata
}

\begin{abstract}
Purpose: To investigate the treatment outcomes of argon laser peripheral iridoplasty (ALPI) in angle closure mechanisms other than pupillary block.

Methods: We conducted a comprehensive chart review to evaluate consecutive patients who underwent ALPI due to unsuccessful laser iridotomy (whenever the angles remained occludable) between July 2009 and April-2012. An occludable angle was defined as the posterior trabecular meshwork not visible for $\geq 180^{\circ}$ without indentation on dark room gonioscopy. Eyes with previous incisional surgery or more than $90^{\circ}$ of peripheral anterior synechiae were excluded. Main data collected were age, presence of glaucoma, pre- and postlaser intraocular pressure (IOP), angle-status, and underlying angle closure mechanism. Main outcomes were postALPI angle widening on gonioscopy and magnitude of IOP reduction.
\end{abstract}

Results: A total of 41 eyes (27 patients) with persistent occludable angles were initially included in the analysis, comprising approximately $14 \%$ of the 196 patients (321 eyes) that had undergone laser iridotomy during the predefined period. Among these cases, most common angle closure mechanisms were plateau iris (56\%) and lens-induced component (34\%). Patients with plateau iris were mostly women and younger than those with lens-induced component $(p \leq 0.03)$. A total of 35 eyes (23 patients) underwent ALPI (63\% had glaucoma). Mean IOP was significantly reduced from $18.2 \pm 4.7$ to $14.6 \pm 3.8(p<0.01)$, with no significant difference between patients with plateau iris and lens-induced components $(p=0.22)$. Over $91 \%$ of these eyes showed nonoccludable angles following ALPI (follow-up of $11.8 \pm 3.3$ months).

Conclusion: In this series of middle-aged patients with occludable angles, despite a patent iridotomy, ALPI was a useful procedure independent of the underlying mechanism, leading to angle widening and moderate IOP reduction in most cases.

Keywords: Angle closure, Nonpupillary block mechanisms, Plateau iris, Laser peripheral iridoplasty.

${ }^{1}$ Resident, ${ }^{2,7}$ Associate Professor, ${ }^{3-5}$ Medical Staff,

${ }^{6}$ Glaucoma Fellow

${ }^{1,4}$ Department of Ophthalmology, Glaucoma Services, Federal University of São Paulo, São Paulo, Brazil

${ }^{2}$ Department of Ophthalmology, Glaucoma Anterior Segment Surgery, Mayo Clinic, Jacksonville, Florida, USA

3,5-7 Department of Ophthalmology, Glaucoma Services, Federal University of São Paulo, Hospital Medicina dos Olhos, São Paulo, Brazil

Corresponding Author: Tiago Santos Prata, Associate Professor, Department of Ophthalmology, Glaucoma Services Federal University of São Paulo, Rua Botucatu, 821 Vila Clementino, São Paulo-04023-062, Brazil, Phone: 551150852010 Fax: 551150852000, e-mail: tiagoprata@ig.com.br
How to cite this article: Prado VG, Dorairaj S, Biteli LG, Sousa AKS, Moreno PAM, Lopes FS, Prata TS. Role of Laser Iridoplasty in the Management of Angle Closure Mechanisms other than Pupillary Block. J Curr Glaucoma Pract 2014;8(2):82-84.

\section{Source of support: Nil}

\section{Conflict of interest: None}

\section{INTRODUCTION}

Relative pupillary block is considered the primary mechanism for angle-closure. ${ }^{1-3}$ Although laser peripheral iridotomy (LPI) remains the cornerstone of angle closure management, it does not widen the angle in all cases, as approximately 20 to $30 \%$ of these patients continue to have appositional angle closure in the presence of a patent iridotomy. ${ }^{1-3}$ In these cases, nonpupillary block mechanisms, such as lensinduced, plateau iris and peripheral angle crowding, may be involved. ${ }^{4-7}$ Argon laser peripheral iridoplasty (ALPI) and lens extraction have been suggested as effective procedures to manage eyes with persistent occludable angle..$^{8-10}$

Looking carefully at previously published data, most studies have focused on ALPI effects exclusively in eyes with plateau iris component ${ }^{9}$ or have not specifically defined the underlying angle closure mechanism. In this study, we aimed to investigate the efficacy of ALPI in consecutive eyes with occludable angles despite a patent iridotomy, independent of the underlying angle closure mechanism.

\section{METHODS}

After Institutional Review Board approval, we conducted a comprehensive chart review to evaluate consecutive patients who underwent ALPI due to occludable angles between July 2009 and April 2012. An occludable angle was defined as the posterior trabecular meshwork not visible for $\geq 180^{\circ}$ without indentation on dark room gonioscopy. We included in the analysis all cases that required ALPI due to unsuccessful laser iridotomy (whenever the angles remained occludable). Eyes with previous incisional surgery, with more than $90^{\circ}$ of peripheral anterior synechiae, ocular trauma, uveitis, or any other form of secondary glaucoma were excluded.

Data collected were: age, gender, race, presence of glaucoma, pre- and postlaser intraocular pressure (IOP), number of antiglaucoma medications, angle-status, and underlying angle 
closure mechanism as determined by gonioscopy (ultrasound biomicroscopy was used whenever necessary), and subsequent management during follow-up. On gonioscopy, eyes considered to have lens-induced component were those in which the lens extended nearly to the angle wall, so that indentation produced a narrow, inverted triangular space and the iris contour remained smoothly domed into its insertion point. Eyes in which the 'double hump' sign was identified during indentation were considered to have plateau iris component. Main outcomes were post-ALPI angle widening on gonioscopy and magnitude of IOP reduction.

\section{RESULTS}

A total of 41 eyes (27 patients) with persistent occludable angles despite a patent LPI were initially included in the analysis, comprising approximately $14 \%$ of the 196 patients (321 eyes) that had previously undergone iridotomy during the predetermined period. Among these 41 cases, most common angle closure mechanisms were plateau iris (56\%) and lens-induced component (34\%). Patients with plateau iris were mostly women (75\%) and younger (mean age, 55.3 years) than those with lens-induced component (mean age, 64.8 years; $30 \%$ were women; $\mathrm{p} \leq 0.03$ ). Table 1 provides clinical characteristics of these patients.

Most of these cases of persistent occludable angles, following LPI, were treated with ALPI ( $85 \%$; 23 patients 35 eyes). Overall, glaucoma was found in $63 \%$ of the eyes undergoing iridoplasty. The average number of preoperative medications was $1.5 \pm 1.1$. Treatment regimen was not changed until the last follow-up visit. IOP was significantly reduced from $18.2 \pm 4.7$ to $14.6 \pm 3.8(\mathrm{p}<0.01)$, with no significant difference between patients with plateau iris and lens-induced components ( $p=0.22$; follow-up of $11.8 \pm 3.3$ months). Over $91 \%$ of the eyes showed nonoccludable angles

Table 1: Characteristics of patients with persistent occludable angles following laser peripheral iridotomy*

\begin{tabular}{ll}
\hline Variables & Patients ( $n=27 ; 41$ eyes) \\
\hline Mean age (years) & $58.9 \pm 11.8$ \\
Gender (\%) (men/women) & $44 / 56$ \\
Race (\%) (White/Black/Asian & $78 / 15 / 7$ \\
descendant) & \\
Presence of glaucoma (\% of eyes) & $68 \%$ (28 out of 41 eyes) \\
Angle-closure mechanisms(\%) & $56 / 34 / 10$ \\
(PIC/LIAC/others) & \\
Mean IOP before ALPI (mm Hg) & $18.2 \pm 4.7$ \\
Mean IOP after ALPI (mm Hg) & $14.6 \pm 3.8$ \\
\hline *Data are given as mean \pm standard deviation whenever indicated \\
PIS: Plateau iris component; LIAC: Lens-induced angle-closure; \\
IOP: Intraocular pressure; ALPI: Argon laser peripheral iridoplasty
\end{tabular}

following ALPI. In one case, filtering surgery was required to achieve adequate IOP control.

\section{DISCUSSION}

While dealing with cases of angle closure (with or without glaucoma), identification of the underlying mechanism is of utmost importance as each may have a different course and require a different treatment approach. Although there is extensive information in the literature regarding the main etiologies and management guidelines of primary angle closure in several populations, there are scant data when it comes to South American patients (Brazilians, more specifically). ${ }^{1,11-16}$ Evaluating a large series of patients with primary angle closure (with and without glaucoma), we determined the most frequent underlying mechanisms and the outcomes of laser treatment. To the best of our knowledge, this is the first study to report on such findings in a large sample of South American patients.

We believe it is important to discuss the clinical implications of our findings. Primary angle closure glaucoma is a leading cause of bilateral blindness worldwide. ${ }^{16}$ Treatment of primary angle closure is directed toward two goals: eliminate the mechanism of angle closure and control any remaining IOP elevation. ${ }^{14}$ Although laser iridotomy is currently the first line of treatment, many eyes will continue to have appositional angle closure and an additional treatment option might be necessary. ${ }^{1,3}$ In this large consecutive series, ALPI was highly effective in eliminating residual appositional angle closure caused by mechanisms other than pupillary block. In addition, we documented a $20 \%$ IOP reduction on average. Our results not only confirm the important role of ALPI in cases of plateau iris, ${ }^{9}$ but also suggest it as an effective alternative in cases of lens-induced component. We believe this is clinically meaningful, as not every case of lens-induced angle closure coexists necessarily with a symptomatic cataract. This seems to be the case with our study population, as its mean age was under 60 years (mean age $58.3 \pm 11.6$ years considering the 196 patients). It is noteworthy that ALPI has also been successfully used as an initial treatment to break acute phacomorphic attacks. ${ }^{17}$ As additional findings, our plateau iris patients tended to be women and younger than those with lens-induced component; ALPI effectiveness being similar in both angle closure mechanisms.

\section{CONCLUSION}

Our findings suggest that a significant proportion of patients with angle closure were not completely treated with LPI. In these large series of middle-aged patients with angle closure 
originating mainly at an anatomic level posterior to the iris, ALPI was a useful procedure independent of the underlying mechanism, leading to angle widening and moderate IOP reduction in most cases. A detailed eye exam with indentation gonioscopy should always be performed after LPI to rule out persistent angle closure due to nonpupillary block mechanisms.

\section{REFERENCES}

1. Thomas R, Arun T, Muliyil J, George R. Outcome of laser peripheral iridotomy in chronic primary angle closure glaucoma. Ophthalmic Surg Lasers 1999 Jul-Aug;30(7):547-553.

2. He M, Friedman DS, Ge J, Huang W, Jin C, Lee PS, Khaw PT, Foster PJ. Laser peripheral iridotomy in primary angle-closure suspects: biometric and gonioscopic outcomes: the Liwan Eye Study. Ophthalmology 2007 Mar;114(3):494-500.

3. Chandler PA. Narrow-angle glaucoma. AMA Arch Ophthalmol 1952 Jun;47(6):695-716.

4. Prata TS, Dorairaj S, De Moraes CG, Tello C, Liebmann JM, Ritch R. Indentation slitlamp-adapted optical coherence tomography technique for anterior chamber angle assessment. Arch Ophthalmol 2010 May;128(5):646-647.

5. Shabana N, Aquino MC, See J, Ce Z, Tan AM, Nolan WP, Hitchings R, Young SM, Loon SC, Sng CC, et al. Quantitative evaluation of anterior chamber parameters using anterior segment optical coherence tomography in primary angle closure mechanisms. Clin Experiment Ophthalmol 2012 Nov;40(8):792-801.

6. He M, Foster PJ, Johnson GJ, Khaw PT. Angle-closure glaucoma in East Asian and European people. Different Diseases? Eye (Lond) 2006 Jan;20(1):3-12.
7. Tornquist R. Angle-closure glaucoma in an eye with a plateau type of iris. Acta Ophthalmol (Copenh) 1958;36(3):419-423.

8. Ming Zhi Z, Lim AS, Yin Wong T. A pilot study of lens extraction in the management of acute primary angle-closure glaucoma. Am J Ophthalmol 2003 Apr;135(4):534-536.

9. Ritch R, Tham CC, Lam DS. Long-term success of argon laser peripheral iridoplasty in the management of plateau iris syndrome. Ophthalmology 2004 Jan;111(1):104-108.

10. Gunning FP, Greve EL. Lens extraction for uncontrolled angleclosure glaucoma: long-term follow-up. J Cataract Refract Surg 1998 Oct;24(10):1347-1356.

11. Nolan WP, Foster PJ, Devereux JG, Uranchimeg D, Johnson GJ, Baasanhu J. YAG laser iridotomy treatment for primary angle closure in east Asian eyes. Br J Ophthalmol 2000 Nov;84(11):1255-1259.

12. Sakata K, Sakata LM, Sakata VM, Santini C, Hopker LM, Bernardes R, Yabumoto C, Moreira AT. Prevalence of glaucoma in a South Brazilian population: Projeto Glaucoma. Invest Ophthalmol Vis Sci 2007 Nov;48(11):4974-4979.

13. Cumba RJ, Nagi KS, Bell NP, Blieden LS, Chuang AZ, Mankiewicz KA, Feldman RM. Clinical outcomes of peripheral iridotomy in patients with the spectrum of chronic primary angle closure. ISRN Ophthalmol 2013 Jun;2013:828972.

14. AAO PPP Glaucoma Panel. Primary Angle Closure PPP - 2010. Am Acad Ophthalmol 2010 Oct.

15. See JL, Aquino MC, Aduan J, Chew PT. Management of angle closure glaucoma. Indian J Ophthalmol 2011 Jan;(59 Suppl): 82S-87S.

16. Foster PJ, Johnson GJ. Glaucoma in China: how big is the problem? Br J Ophthalmol 2001 Nov;85(11):1277-1282.

17. Tham CC, Lai JS, Poon AS, Chan JC, Lam SW, Chua JK, Lam DS. Immediate argon laser peripheral iridoplasty (ALPI) as initial treatment for acute phacomorphic angle-closure (phacomorphic glaucoma) before cataract extraction: a preliminary study. Eye (Lond) 2005 Jul;19(7):778-783. 